Im Frühjahr dieses Jahres ging die Nachricht durch die Medien: In einer Schulprojektwoche zur „Steinzeit“ wurde vor Fünftklässlern ein Kaninchen getötet und verspeist. Drei Tage arbeitete ein Landwirt, selbst Sozialpädagoge und Vater, mit den Kindern zusammen, um sie auf das anstehende Ereignis

\section{Schlachtung als Bildungsereignis}

Der Tod eines Kaninchens im Unterricht vorzubereiten. Dennoch versuchten einige von ihnen mit einer Unterschriftensammlung die Schlachtung zu verhindern, wenn auch ohne Erfolg. Öffentlich wurde das Ganze, weil Eltern einer Zeitung von ihren schockierten Kindern berichteten. Gegen Landwirt und Schulleitung wurde wegen Körperverletzung und Missbrauch von Tieren Anzeige erstattet. Auch Schulaufsicht und

Kinderschutzbund verurteilten den Vorgang. Jeden Tag werden bei uns zahllos Tiere getötet und verzehrt. Warum wird dieses Schulprojekt nun zum Skandal, der Bildungsverantwortliche, Eltern, Kinderschützer, die Justiz und Medien auf den Plan ruft? Offenbar sind Tabus verletzt worden, die uns ansonsten mit dem Alltag der Tiertötungen ruhig leben lassen. Schlachttierhaltung und Schlachtung sind erfolgreich hinter die Kulissen des öffentlichen Lebens abgedrängt, es findet in abgeschirmten Reservaten statt. Elias hat in seiner Zivilisationstheorie nachgezeichnet, wie die allmähliche Ausgrenzung der offenen Gewalt aus dem gesellschaftlichen Leben dafür gesorgt hat, dass alles, was an die Grausamkeiten des Lebens erinnern könnte, vor unseren Augen versteckt werden muss, weil es für uns unerträglich geworden ist. Wenn also nun ein Kaninchen in der Schule geschlachtet wird, zerrt dies etwas Verdrängtes und Verpöntes hinter den Kulissen wieder hervor und platziert es inmitten der Öffentlichkeit. Nicht die Schlachtung selbst ist dabei die erschreckende Tabuverletzung, sondern die Arena, in der sie stattfindet. Sie ist sittenwidrig, weil sie in einer Schule vollzogen wird und das Publikum Kinder sind, die uns besonders verletzbar durch Gewaltdarstellungen erscheinen. Umso unverantwortlicher ist eine Schule, die Kindern eine Kaninchenschlachtung zumutet. Doch ist sie es tatsächlich?

Die Kindheitsforscher Behnken/Zinnecker sprachen einmal von der „pädagogisch induzierten Dummheit“, die bei Kindern gerade dadurch entsteht, dass ihnen - gutgemeint - unverstellte Erfahrungen in den öffentlichen Räumen der Erwachsenenwelt vorenthalten werden. Die pädagogische Paradoxie besteht darin, dass die kindlichen Erfahrungswelten zunächst entleert werden, um sie dann durch Zonen künstlich arrangierter und bereinigter Lernarrangements wieder zu füllen. Die Realitäten der Tiertötung vor Kindern zu verstecken, mag ihnen - und den Erwachsenen - in gewisser Weise sicherlich gut tun. Es macht sie aber auch realitätsuntüchtig und ängstlich. Sie werden in Distanz zu brisanten Alltäglichkeiten des Lebens gehalten, die essentielle ethische Fragen aufwerfen, Auseinandersetzung und einen haltenden Rahmen brauchen. Auch ändert das Tabu schließlich nichts an der schrecklichen Tö-

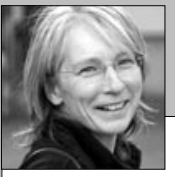
tungsrealität, vielmehr wird diese umso bedrohlicher, je mehr sie gemieden wird. Irgendwann bricht sie ins eigene Leben - spätestens beim nächsten Fleischskandal. Und schließlich: Das Tabu sichert ab, dass industrielle Massentierhaltung und -schlachtung ungestört weiter geführt werden können, den Schuldkonflikt des Fleischkonsumenten immer weiter vergrößern und damit wiederum den Tabudruck verstärken.

Von daher könnte der Medienfall ein guter Anlass zu einer Debatte um pädagogische Schlüsselfragen sein. Wie sieht Bildung zur Realitätstüchtigkeit aus? Dürfen Kinder von den Hintergründen ihrer Fleischmahlzeit nichts wissen? Wie sollen sie davon erfahren? Dass die Schüler eine Petition gegen die Schlachtung organisierten, kann eigentlich ermutigen. Dass diese jedoch nach Medienberichten von Lehrerseite für Unsinn erklärt wurde, denn man kann schließlich auch nicht gegen eine Klassenarbeit protestieren, ist vielleicht das wirklich Fragwürdige dieser Schulaktion - eine verpasste Bildungsgelegenheit. 